\title{
INSULIN AUTOIMMUNE SYNDROME - A RARE CAUSE OF HYPOGLYCAEMIA: A REPORT ON 2 CASES
}

\section{Cooray $\mathrm{MSA}^{1}$, Somasundaram $\mathrm{NP}^{1}$, Liyanarachchi $\mathrm{KD}^{1}$, Sumanathilleke $\mathbf{M}^{2}$}

${ }^{1}$ Diabetes and Endocrine unit, National Hospital of Sri Lanka. 2Diabetes and Endocrine unit, Teaching Hospital, Karapitiya.

\begin{abstract}
Insulin autoimmune syndrome (IAS, Hirata disease) is a rare cause of hypoglycaemia in countries other than Japan and Korea. It is a syndrome of hypoglycaemia with elevated insulin and insulin antibody levels. Although there is a genetic basis to the disease, many drugs and autoimmune conditions such as Graves' disease have been implicated in the pathogenesis. Here we report two cases of IAS identified in Sri Lanka.
\end{abstract}

Case 1: A 47-year-old previously healthy male patient presented with neuroglycopenic symptoms and seizures with low blood glucose levels in a background of high insulin levels. Conventional imaging was negative for a pancreatic tumour. Calcium stimulation testing revealed very high basal insulin levels from all regions of the pancreas. Insulin antibodies were above the normal levels. A diagnosis of IAS was made and steroids and frequent small meals containing complex carbohydrates was started as treatment. In spite of treatment, the patient continued to have high insulin levels, but free of symptoms.

Case 2: A 37-year-old female with Graves' disease who was treated with carbimazole, presented with hypoglycaemic episodes that occur 4 to 6 hours after meals. Investigations revealed high insulin levels in the presence of hypoglycaemia, which occurred 6 hours into the prolonged fasting test. Imaging by CT, MRI and endoscopic ultrasonography yielded negative results. She had very high insulin autoantibody levels. A diagnosis of IAS secondary to carbimazole was made and the anti-thyroid drugs were withdrawn. Her symptoms resolved and her biochemistry got normalized with drug withdrawal.

Key words: Hypoglycaemia, Hyperinsulinaemia, Insulin, Insulin antibodies

\section{INTRODUCTION}

Insulin autoimmune syndrome (IAS, Hirata disease) is an unusual cause of hypoglycaemia. It is characterized by spontaneous hypoglycaemia and extremely high insulin levels in the presence of circulating insulin antibodies in patients who have never been exposed to exogenous insulin. Although IAS is considered to be the third commonest cause of hypoglycaemia in Japan, only a handful of cases have been reported elsewhere (2).

\section{CASE REPORT}

\section{Case 1:}

Mr. I, a 47-year-old driver who had been previously healthy, presented to the local hospital with early morning seizures. He was found to be hypoglycaemic with a capillary glucose of $23 \mathrm{mg} / \mathrm{dl}$ and his symptoms improved following the administration of intravenous dextrose. He admitted that he was having intense hunger especially after going to bed several weeks prior to the presentation. He had several episodes of confusion, slurred speech and abnormal behaviour in the mornings. These symptoms improved after having his tea with sugar or breakfast in the morning. Due to his increased appetite, he was eating frequently and he had gained weight noticeably during the past 3 months.
He denied any other constitutional symptoms, postural dizziness, pigmentation or any other symptoms suggestive of hypocortisolaemia. There were no skin lesions nor was there any history of constipation, perioral numbness or dyspeptic symptoms suggestive of hyperparathyroidism. There was no family history of any pituitary, adrenal or pancreatic tumours. The patient had never undergone abdominal surgeries and had never received insulin injections or medicines such as sulfhydryl compounds. There was no history of diabetes.

His body mass index was $29 \mathrm{~kg} / \mathrm{m}^{2}$. There was no hyperpigmentation, lymphadenopathy, peripheral stigmata of chronic liver cell disease, goitre or lesions or lumps which resemble neurofibromatosis or angiofibromas. His baseline haematology as well as serum electrolytes, renal profile and liver profile were within normal levels and as follows (Table 1). His C peptide level assessed during the initial presentation with hypoglycaemia was found to be at 1014 (132 $690 \mathrm{pmol} / \mathrm{l})$. Serum insulin level could not be done at this setting.

Endogenous hyperinsulinemia was suspected and 5-hour oral glucose tolerance test was performed to confirm our clinical suspicion. The patient developed hypoglycaemia with a capillary blood sugar of $38 \mathrm{mg} / \mathrm{dl}, 3$ hours into 
the prolonged fasting test (Table 2). The $\mathrm{C}$ peptide and insulin levels at that time were $5.47 \mathrm{ng} / \mathrm{ml}(0.9-7.1)$ and 645 micro units/ml (2.6-24.9) respectively. At the time of hypoglycaemia, the serum insulin and $\mathrm{C}$ peptide levels were 1000 micro units $/ \mathrm{ml}$ and $1.4 \mathrm{ng} / \mathrm{ml}$ respectively. Urine Sulphonylurea screen was negative.

\section{Table 1: Baseline biochemical investigations}

$\begin{array}{ll}\text { AST } & 18 \mathrm{IU} / \mathrm{L} \\ \text { ALT } & 10 \mathrm{IU} / \mathrm{L} \\ \text { Alkaline phosphatase } & 162 \mathrm{IU} / \mathrm{L} \\ \text { Serum bilirubin } & 10 \mathrm{micromol} / \mathrm{L} \\ \text { Serum protein } & 50 \mathrm{~g} / \mathrm{L} \\ \text { Albumin } & 40 \mathrm{~g} / \mathrm{L} \\ \text { Globulin } & 7 \mathrm{~g} / \mathrm{L} \\ \text { PT / INR } & 1.03 \\ \text { Blood urea } & 5 \mathrm{mmol} / \mathrm{L} \\ \text { Serum creatinine } & 85 \mathrm{mmol} / \mathrm{L} \\ \text { Serum sodium } & 132 \mathrm{mmol} / \mathrm{L} \\ \text { Serum potassium } & 4.2 \mathrm{mmol} / \mathrm{L} \\ \text { Serum calcium } & 2.4 \mathrm{mmol} / \mathrm{L}(2.1-2.6) \\ \text { ESR } & 29 \mathrm{~mm} / 1 \mathrm{st} h o u r \\ \text { TSH } & 1.83 \mathrm{miu} / \mathrm{L}(0.47-4.7) \\ \text { Free T4 } & 15.9 \mathrm{picomol} / \mathrm{L}(10-28.2) \\ \text { Serum cortisol }(30 \text { minutes } & 642 \mathrm{nmol} / \mathrm{L}(>550) \\ \text { after synacthen }) & \end{array}$

Abdominal ultrasound scanning and computed tomography of abdomen did not reveal any focal lesion of the pancreas. Magnetic Resonance Imaging (MRI) of the pancreas also failed to reveal any focal lesions. Endoscopic ultrasound revealed a normal pancreas. Pancreatic arteriography with selective arterial calcium stimulation and hepatic venous sampling (ASVS) was performed. During the test the patient was given a continuous infusion of dextrose in order to maintain the blood sugar levels between $90-120 \mathrm{mg} / \mathrm{dl}$. The venous sampling demonstrated high basal levels of insulin from all regions of the pancreas. However, the results were not suggestive of a pancreatic tumour (Table 3 ).

At this stage insulin auto-antibody (IAA) levels were assessed and found to be elevated at $>300 \mathrm{u} / 1(>12$ is positive).
Insulin autoimmune syndrome was identified as the cause of the hypoglycaemia. He was started on a steroid regime with Prednisolone $60 \mathrm{mg}$ daily, which was then tailed off slowly over a period of 3 months. The frequency and severity of hypoglycaemic episodes reduced markedly and the patient was advised on a dietary regime with frequent small meals with complex carbohydrates. The patient has continued to have hypoglycaemic episodes. However, the attacks were less frequent and less severe. Currently the patient is maintained on a balanced diet with complex carbohydrates without any medication.

Table 2: 5-hour oral glucose tolerance test revealed oral glucose intolerance with reactive hypoglycaemia at 180 minutes

\begin{tabular}{cc}
\hline Time & $\begin{array}{l}\text { Plasma glucose } \\
(\mathrm{mg} / \mathrm{dl})\end{array}$ \\
\hline $0 \mathrm{~min}$ & 68 \\
$60 \mathrm{~min}$ & 196 \\
$120 \mathrm{~min}$ & 228 \\
$180 \mathrm{~min}$ & 34 \\
$240 \mathrm{~min}$ & 62 \\
\hline
\end{tabular}

\section{Case 2:}

A 37-year-old lady presented to the endocrinology clinic with symptoms of thyrotoxicosis over a period of 1 month. However, there was no history of diabetes or thyroid disorders in the past. Her Free T4 was $3.1 \mathrm{ng} / \mathrm{dl}$ and TSH $<0.001 \mathrm{mIU} / 1$. Technetium 99 isotope scanning (figure 1) was suggestive of Graves' disease. She was started on a titration regime of Carbimazole $40 \mathrm{mg}$ day.

Two months after starting the treatment, she presented with symptomatic hypoglycaemia 4 hours after breakfast. The blood glucose was found to be $2.4 \mathrm{mmol} / 1$. She denied taking any drugs causing hypoglycaemia. Her fasting glucose level was $2.5 \mathrm{mmol} / 1$ with serum insulin and serum $\mathrm{C}$ peptide level of 35.3 micro unit $/ \mathrm{ml}$ and $2.1 \mathrm{ng} / \mathrm{ml}$ respectively. Abdominal MRI scans revealed normal pancreas. Serum Insulin antibodies was strongly

Table 3: Result of the calcium stimulation test

\begin{tabular}{|c|c|c|c|c|c|c|c|c|}
\hline \multirow[b]{2}{*}{ Time } & \multicolumn{2}{|c|}{ Superior mesenteric vein } & \multicolumn{2}{|c|}{ Proper hepatic vein } & \multicolumn{2}{|c|}{ Gastro-duodenal vein } & \multicolumn{2}{|c|}{ Spleenic vein } \\
\hline & $\begin{array}{r}\text { RBS } \\
(\mathrm{mg} / \mathrm{dL})\end{array}$ & $\begin{array}{l}\text { Insulin } \\
\text { level } \\
(\mu \mathrm{U} / \mathrm{mL})\end{array}$ & $\begin{array}{r}\text { RBS } \\
(\mathrm{mg} / \mathrm{dL})\end{array}$ & $\begin{array}{l}\text { Insulin } \\
\text { level } \\
(\mu \mathrm{U} / \mathrm{mL})\end{array}$ & $\begin{array}{r}\text { RBS } \\
(\mathrm{mg} / \mathrm{dL})\end{array}$ & $\begin{array}{l}\text { Insulin } \\
\text { level } \\
(\mu \mathrm{U} / \mathrm{mL})\end{array}$ & $\begin{array}{r}\text { RBS } \\
(\mathrm{mg} / \mathrm{dL})\end{array}$ & $\begin{array}{l}\text { Insulin } \\
\text { level } \\
(\mu \mathrm{U} / \mathrm{mL})\end{array}$ \\
\hline$-120 \mathrm{sec}$ & 93 & 704 & 112 & 904 & 108 & 951 & 107 & 900 \\
\hline $30 \mathrm{sec}$ & 94 & 702 & 102 & 944 & 107 & 953 & 105 & 869 \\
\hline $60 \mathrm{sec}$ & 94 & 718 & 109 & 961 & 105 & 917 & 107 & 971 \\
\hline
\end{tabular}


positive at $299.85 \mathrm{u} / \mathrm{ml}(>18$ is positive and $<12$ negative).

\section{Figure 1:}

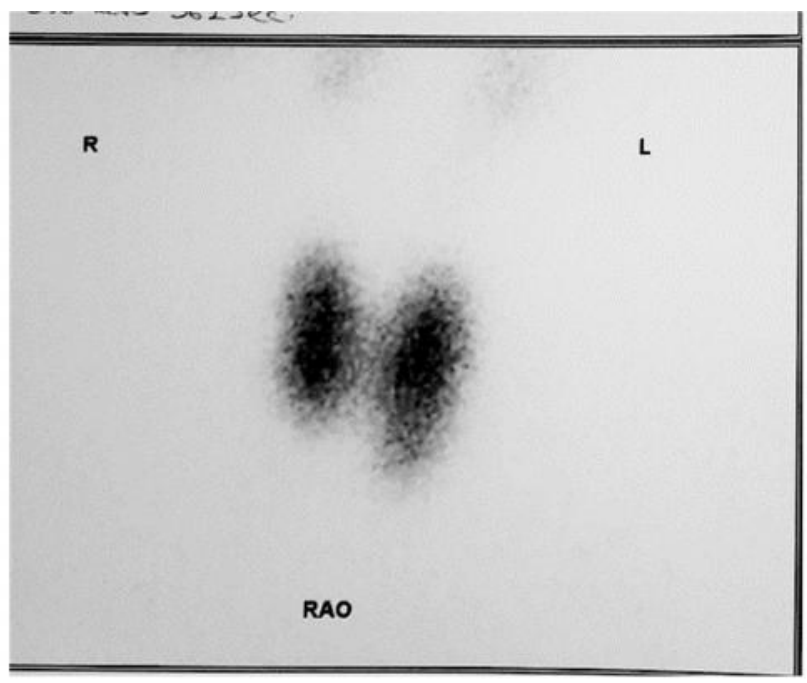

The diagnosis of Carbimazole induced IAS was made. Discontinuation of carbimazole resulted in complete resolution of hypoglycaemia with normalisation of fasting glucose, insulin and C-peptide levels. Thyroidectomy was planned as definitive therapy for thyrotoxicosis after controlling thyroid activity with alternative drugs.

\section{DISCUSSION}

Insulinoma is considered as the most important cause for hyper-insulinaemic hypoglycaemia and when patients present with this entity, the evaluation process is mainly focused on identifying an insulinoma. Even after identifying a tumour in the pancreas, question arises as to whether there is a tumour elsewhere or whether there is any other cause for the hypoglycaemia. Insulin autoantibody syndrome is a rare cause of hyperinsulinaemic hypoglycaemia that should be considered especially in patients with negative results with localization studies.

Insulin Autoimmune Syndrome (IAS) or Hirata Disease (HD), was first described by Hirata in 1970 (1) is a syndrome characterized by hyperinsulinaemic hypoglycaemia with high titres of serum insulin and increased levels of insulin autoantibodies, in patients who have had no previous exposure to insulin. It is a syndrome that has been reported mainly in Japanese subjects and it has shown to be 10 to 30 times more prevalent in Japanese and Koreans than in Caucasians $(2,3)$. Nevertheless, IAS has also been reported in non-Japanese subjects and there have been few cases reported in Caucasian and East Asian populations $(4,5)$. This is probably the first 2 reported cases of IAS in Sri Lankan patients.

Specific class II alleles have been implicated for the development of IAS and it has been linked to drugs containing the sulfhydryl group in genetically susceptible individuals. It is believed that the drugs containing the sulfydryl goup interfere with the disulphide bond of insulin leading to the generation of autoimmunity by various mechanisms. The drugs such as Methimazole, Glutathione, Alpha-mercaptopropionyl glycine, Alphalipoic-acid, Tolbutamide, Imipenem and Hydralazine are usually implicated with the development IAS. In a Japanese case series, almost $70 \%$ of the patients reported previous exposure to methimazole $(49 \%)$, alpha mercaptopropionyl glycine $(43 \%)$, or glutathione $(8 \%)$ and stopping the offending drug has reverse hypoglycaemia.

The characteristic feature of IAS is the extremely high insulin levels. This occurs partly as a consequence of the insulin antibodies, which interfere with the insulin radioimmunoassay (RIA). If a double antibody technique is employed (using RIA), the insulin antibodies can increase the immuno-reactive insulin by competing with anti-insulin antibodies (3). On the other hand, an immuno-radiometric assay (IRMA) may have lower false-positive rates and, therefore, be more reliable (3).

Graves' disease is an autoimmune disease that could be linked to the development of autoimmunity in IAS (2). In case 2 , the patient developed symptoms after starting carbimazole and hypoglycaemic symptoms resolved following drug withdrawal. This favours the development of drug induced IAS. However, our $1^{\text {st }}$ patient did not give a history of drug exposure that could be implicated to the development of IAS. Both patients had symptoms 3 to 5 hours after meals, which is typical of IAS. However, the symptoms have been described even later than this in some patient with IAS (7). During the early postprandial period, the auto-antibodies get bound to the insulin secreted by the pancreas and mask the biological activity of insulin. This may lead to a diabetic range glycaemic response, which keep the insulin secretion stimulated for a longer duration of time. During the post-prandial phase, as the blood glucose levels decline, there is an erratic dissociation of insulinantibody complexes, which results in an inappropriately high free insulin concentrations leading to prandial hypoglycaemia $(3,6)$.

Small frequent meals that could prevent the rapid elevation of plasma glucose (glucose spike) are an effective way of preventing hypoglycaemia. The current recommendations are to give six or more small meals and to avoid sweets except at the time of hypoglycaemic attacks (2, 3). The auto-antibodies spontaneously disappear within several months to several years (8) and it has been reported that more than $80 \%$ of the patients develop remission within less than three months after the causative drug withdrawal. Steroids, plasmapheresis, and immunosuppressive drugs can also be used fasten this process. However, there is no place for surgical management. In our $1^{\text {st }}$ patient, the clinical condition improved following steroids treatment and he remained off steroids with minimal hypoglycaemia. The patient in case 2 had resolution following drug withdrawal and did not need any other treatment. 


\section{CONCLUSIONS}

Insulinoma is the most important cause that is considered during the investigations of hyperinsulinemic hypoglycaemia. In the backdrop of negative imaging, IAS is an important rare cause that needs to be considered in the differential diagnosis of spontaneous hypoglycaemia especially in the setting of an autoimmune disease and when the patients are receiving treatment with the implicated drugs. IAS is a cause of hypoglycaemia that can be cured without surgery and careful investigation of the patient with hyperinsulinemic hypoglycaemia for autoimmune mechanisms could prevent unnecessary surgical procedures.

\section{REFERENCES}

1. Hirata $\mathrm{Y}$, Ishizu $\mathrm{H}$, Ouchi $\mathrm{N}$ et al. Insulin autoimmunity in a case of spontaneous hypoglycaemia. Journal of the Japan Diabetes Society. 1970; 13: 312-320.

2. Uchigata Y, Hirata Y. Insulin autoimmune syndrome (IAS, Hirata disease). Annales de Medicine Interne Journal. 1999; 150(3): 245-253.

3. Redmon JB, Nuttall FQ. Autoimmune hypoglycemia. Endocrinology Metabolism Clinics of North America. 1999; 28(3): 603-618.

4. Uchigata $\mathrm{Y}$, Hir ata SY, Iwamoto Y. Insulin autoimmune syndrome (Hirata Disease): Epidemiology in Asia including Japan. Diabetology International. 2010; 1: 21-25.

5. Lup sa BC, Chong AY, Cochran EK, Soos M A, Semp le RK, Gorden P. Autoimmune forms of hypoglycaemia. Medicine (Baltimore). 2009; 88: 141-153.

6. Miyamura $\mathrm{N}$, Murata $\mathrm{Y}$, Taketa $\mathrm{K}$, Ichihara $\mathrm{Y}$, Tokunaga H, Araki E et al. A case of insulin autoimmune syndrome with HLA RB1*0404: impact on the hypothesis for the molecular pathogenesis involving DRB1 molecules. Diabetic Medicine. 2006; 23: 104-105.

7. Taylor SI, Barbetti F, Accili D, Roth J, Gorden P. Syndromes of autoimmunity and hypoglycemia. Autoantibodies directed against insulin and its receptor. Endocrinology Metabolism Clinics of North America. 1989; 18: 123-143.

8. Uchigata Y, Eguchi Y, Takayama-Hasumi S, Omori Y. Insulinautoimmune syndrome (Hirata disease): clinical features and epidemiology in Japan. Diabetes Research Clinic Practice. 1994; 22: 89-94. 